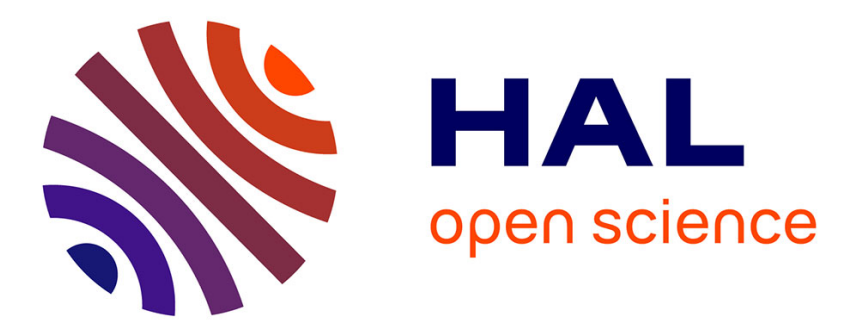

\title{
The isolated N-terminal domains of TIMP-1 and TIMP-3 are insufficient for ADAM10 inhibition
}

Magdalini Rapti, Susan J Atkinson, Meng-Huee Lee, Andrew Trim, Marcia Moss, Gillian Murphy

\section{- To cite this version:}

Magdalini Rapti, Susan J Atkinson, Meng-Huee Lee, Andrew Trim, Marcia Moss, et al.. The isolated N-terminal domains of TIMP-1 and TIMP-3 are insufficient for ADAM10 inhibition. Biochemical Journal, 2008, 411 (2), pp.433-439. 10.1042/BJ20071430 . hal-00478897

\section{HAL Id: hal-00478897 https://hal.science/hal-00478897}

Submitted on 30 Apr 2010

HAL is a multi-disciplinary open access archive for the deposit and dissemination of scientific research documents, whether they are published or not. The documents may come from teaching and research institutions in France or abroad, or from public or private research centers.
L'archive ouverte pluridisciplinaire HAL, est destinée au dépôt et à la diffusion de documents scientifiques de niveau recherche, publiés ou non, émanant des établissements d'enseignement et de recherche français ou étrangers, des laboratoires publics ou privés. 
THE ISOLATED N-TERMINAL DOMAINS OF TIMP-1 AND TIMP-3 ARE INSUFFICIENT FOR ADAM10 INHIBITION

Magdalini Rapti* ${ }^{\S}$, Susan J Atkinson* ${ }^{\S}$, Meng-Huee Lee*, Andrew Trim ${ }^{\dagger}$, Marcia Moss ${ }^{*}$ and Gillian Murphy*\|.

*Department of Oncology, Cambridge University, Cancer Research UK Cambridge Research Institute, Li Ka Shing Centre, Cambridge CB2 ORE, UK, 'Dept. of Biological Sciences, University of East Anglia, Norwich, NR4 7TJ, UK, Biozyme Inc., Apex, NC 7523, USA.

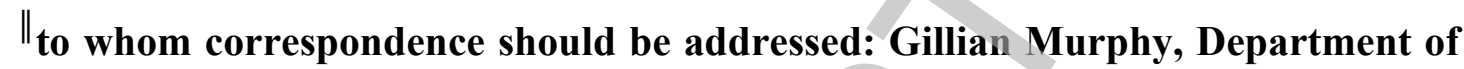
Oncology, Cambridge University, Cancer Research UK Cambridge Research Institute, Li Ka Shing Centre, Cambridge CB2 ORE, United Kingdom. Tel: (+44)1223404470; E-mail: gm290@cam.ac.uk

Abbreviations used: ADAM, a disintegrin and metalloproteinase; TIMP, tissue inhibitor of metalloproteinase; MMP, matrix metalloproteinase; MP, metalloproteinase (of the MMP, ADAM, and ADAM-TS families); tace, TNF alpha convertase, ADAM17; N-TIMP, N-terminal domain of TIMP; N-TIMP-1 ${ }^{\text {tace }}$, the Nterminal domain of TIMP-1 having the following point and region mutations: V4A, TIMP-3ABloop, V69L, T98L; N-TIMP-2 ${ }^{\text {tace }}$, the N-terminal domain of TIMP-2 having the following point and region mutations: S2T, TIMP-3ABloop ,A70S, V71L; N-TIMP$4^{\text {tace }}$, the N-terminal domain of TIMP-4 having the following point mutations: S2T,T38P,E39F,K40G.

Running Title: TIMP inhibition of ADAM10

Key words: ADAM10, TACE, TIMP, inhibition, binding affinity, CD44 shedding

$\S$ these authors contributed equally to this study. 
ADAM10 is a key member of the ADAM family of disintegrin and metalloproteinases which process membrane associated proteins to soluble forms in a process known as 'shedding'. Among the major targets of ADAM10 are Notch, EphrinA2 and CD44. In many cell based studies of shedding the activity of ADAM10 appears to overlap with that of ADAM17 which has a similar active site topology relative to the other proteolytically active ADAMs. The tissue inhibitors of metalloproteinases, TIMPs, have proved useful in the study of ADAM function since TIMP-1 inhibits ADAM10 but not ADAM17, but both enzymes are inhibited by TIMP-3. In this study we show that, in comparison to ADAM17 and the MMPs, the N-terminal domains of TIMPs alone are insufficient for the inhibition of ADAM10.This knowledge could form the basis for the design of directed inhibitors against different metalloproteinases.

\section{INTRODUCTION}

The ADAMs are modular type I transmembrane proteins that contain a metalloprotease and a disintegrin-like domain and are members of the metzincin superfamily (other members include MMPS and ADAMTSs). To date, 13 catalytically active ADAMs have been identified in the human genome. An interesting feature of the ADAMs is that they are involved in proteolytic activity, including the 'shedding' of membrane anchored proteins and also in cellular adhesion [1-2].

The proteolytic activities of the MPs are controlled by their natural inhibitors, the TIMPs (tissue inhibitors of metalloproteinases). To date four variants of human TIMPs exist, TIMPs-1-4, each showing a different inhibition profile against different MPs. For example, the majority of MMPs are well inhibited by all TIMPs but TIMP-1 shows very poor inhibitory activity towards the membranebound MMPs (MT-MMPs) MMP-14, MMP-16, MMP-24 and also towards MMP-19. TIMP-1 is however a good inhibitor of ADAM10 [3]. TIMP-3 inhibits the MMPs, ADAM10, 12 and 17 (TACE) and the aggregan-degrading enzymes ADAMTS-4 and ADAMTS-5 [4-7].

The four TIMPs share a high degree of sequence homology (40-50\%) and a conserved six looped structure. The TIMP polypeptide chain folds into a contiguous elongated domain, with the N-terminal domain comprised of the first three-loops containing three out of six disulfide bonds, and the C-terminal part forming two opposing sub-domains [11]. To date the Nterminal domain has been shown to be sufficient for metalloproteinase inhibition. It contains the major sites of interaction with the catalytic domains of active MPs [8-10].The C-terminal sub-domain is made up from the remaining 40 to 60 amino 
acids. It also contains three disulfide bonds but its conformation is less well defined $[11,12]$. It has been shown to mediate interactions with the catalytic domains of some MMPs and the hemopexin domain of the gelatinases (MMP-2 and MMP-9) [13]. Among the members of the ADAM family, ADAM17 or TNF- $\alpha$-converting enzyme (TACE) has been the most widely studied both in terms of function and TIMP inhibition. ADAM17 is involved in the proteolytic shedding of many cellsurface associated molecules such as proTNF- $\alpha$, Notch, TNF- $\alpha$ receptors I and II and ligands of the epidermal growth factor receptor (EGFR) among others [1, 2]. We have shown that ADAM17 is particularly sensitive to TIMP-3 inhibition and the Nterminal domain, N-TIMP-3, appears to be equally effective $[5,14]$.

Our previous studies on TIMP-MP selectivity were successful in converting the N-terminal domains of TIMP-1, TIMP2 and TIMP-4 into potent inhibitors of ADAM17 by systematic mutagenesis [1518]. In this study we examine the inhibition of ADAM10 by TIMPs. ADAM10 not only shows closer sequence similarity and potential structural features with ADAM1 17 than any other mammalian ADAM, but it is also able to cleave TNF- $\alpha$ based ADAM17 substrates in vitro. In vivo, roles for ADAM10 have been identified in Notch signalling, proteolysis of the cadherins and EphrinA5 [19-21]. Mice lacking ADAM10 die at day 9.5 with multiple defects in the central nervous system and somites [19]. These phenotypes are related to Notch signalling deficiencies. In addition to neural development, ADAM10 seems to be involved in physiological shedding events in the adult brain. Strong evidence suggests that ADAM10 mediates the nonamyloidogenic processing of APP [22]. In cell-based studies, ADAM10 and ADAM17 have been shown to carry out the constitutive and regulated 'normal' processing of the cellular prion protein, respectively [23]. These results suggest that defective or misregulated ADAM10 function might contribute to neurodegenerative processes such as Alzheimer's disease and spongiform encephalopathies.

As part of a programme to understand how TIMPs may be engineered to discriminate between metalloproteinases, we compared the inhibition of ADAM10 by mutant TIMPs to that of ADAM17. We assessed the inhibition of recombinant soluble human ADAM10 by the Nterminal domains of the TIMPs and by the variants that made them active against ADAM17. The kinetic data were compared to the TIMP inhibitory profile towards the activity of native ADAM10 against a physiological substrate, CD44, in a cell based shedding assay. The results obtained lead us to conclude that despite their similarities ADAM10 and ADAM17 are not governed by the same rules where TIMP inhibition is concerned. 


\section{EXPERIMENTAL PROCEDURES}

\section{Materials}

All chemicals and reagents were purchased from Sigma Chemicals (UK) unless otherwise stated. Restriction enzymes and Vent DNA polymerase were obtained from New England Biolabs (UK). The soluble ectodomain of human ADAM10 was obtained from R\&D Systems and the recombinant ADAM10 propeptide was prepared from E.coli [24]. ADAM17 was the kind gift of Dr David Becherer, GlaxoSmithKline Research and Development Inc. North Carolina, USA. For the kinetic experiments the fluorimetric substrate Mca-KPLG LDpa-AR- $\mathrm{NH}_{2}$ was obtained from Calbiochem. Kinetic assays were performed at $27^{\circ} \mathrm{C}$ in fluorescence assay buffer $\left(10 \mathrm{mM} \mathrm{CaCl}_{2}, 50 \mathrm{mM}\right.$ Tris-HCl, $\mathrm{pH}$ 7.5, $0.15 \mathrm{M} \mathrm{NaCl}, 0.05 \%$ Brij-35, $1 \%$ DMSO, $0.02 \% \mathrm{NaN}_{3}$ ) with a Perkin-Elmer LS-50B spectrofluorimeter equipped with thermostatically controlled cuvette holders. The CD44 ELISA kit was purchased from Bender MedSystems Inc. CA, USA.

\section{Antibodies}

Anti-ADAM10 (ab-1) (732-748) rabbit polyclonal antibody was from Calbiochem and anti-ADAM17 (807-823) rabbit polyclonal antibody from Chemicon International. Donkey anti-rabbit IgG conjugated to horseradish peroxidise was from Jackson Immunoresearch. Anti-beta actin monoclonal antibody was from Abcam, UK and anti-alpha tubulin monoclonal antibody from Sigma.

\section{Cell culture}

Human U251 glioblastoma cells were obtained from ECACC and maintained in DMEM medium supplemented with $2 \mathrm{mM}$ glutamine, $100 \mathrm{U} / \mathrm{ml}$ penicillin, $100 \mu \mathrm{g} / \mathrm{ml}$ streptomycin and 10\% FCS. MCF7 cells stably transfected with heparin-binding epidermal growth factor (HB-EGF) conjugated with alkaline phosphatase (MCF-7-HBEGF-AP, clone E12) were a kind gift from Dr Rosalyn Adam, Harvard Medical School, Boston, USA. The cells were maintained in DMEM supplemented with $10 \%$ FCS and $600 \mu \mathrm{g} / \mathrm{ml} \mathrm{G} 418$.

\section{Preparation of TIMPs and Assessment of Activity by Titration}

$\mathrm{N}$-terminal forms of TIMPs-1-4 and the variants designed for ADAM17 inhibition, V4A,TIMP-3ABloop,V69L,T98LNTIMP-1(N-TIMP-1 ${ }^{\text {tace }}$ ),S2T, TIMP3ABloop,A70S,V71LN-TIMP-2(N-TIMP$2^{\text {tace }}$ ) and S2T,T38P,E39F,K40G N-TIMP$4\left(\mathrm{~N}-\right.$ TIMP-4 $\left.{ }^{\text {tace }}\right)$ were prepared from inclusion bodies after expression in E.coli BL21 (DE3) cells and refolded as described previously [16-18]. All proteins were purified by ion-exchange chromatography and their activities were determined by titration against MMP-2 
[15]. For cell studies recombinant TIMPs were prepared as above, dialysed into 50mM HEPES, $150 \mathrm{mM} \mathrm{NaCl} \mathrm{pH} 7.4$ and passed through endotoxin removal columns (EndoTrap ${ }^{\circledR}$ Red, Cambrex Bio Science, USA). Endotoxin levels were assessed before and after treatment using the limulus amebocyte lysate assay (LAL, Cambrex) according to the manufacturer's protocol.

\section{Electrophoretic Techniques}

Proteins were analysed by reduced and non-reduced SDS-PAGE on 13\% polyacrylamide gels followed by staining with Coomassie Brilliant Blue R-250. The presence of single sharp bands with differences in mobility between the two conditions was used to indicate that correct refolding had occurred, in association with active site titration.

\section{Inhibition Constant Measurement $\left(K_{i}^{\text {app }}\right)$}

Recombinant full length human ADAM10 (R\&D) was preincubated with increasing concentrations of the $\mathrm{N}$-terminal or the full-length TIMPs. Incubation was performed at room temperature for $3 \mathrm{~h}$ before steady state measurement (Vs). Reactions were initiated by addition of the quenched fluorescent substrate $(10 \mu \mathrm{M})$. The $K_{i}^{\text {app }}$ was determined from the steadystate rates plotted against TIMP concentration. All data were fitted into the tight binding equation using the computer program Grafit to obtain an estimation of $K_{\mathrm{i}}^{\text {app }}$ values using Equation 1 [16].

$\mathrm{V}_{\mathrm{s}}=\left(\mathrm{V}_{\mathrm{o}} / 2 \mathrm{E}_{\mathrm{t}}\right) \times\left\{\left(\mathrm{E}_{\mathrm{t}^{-}} \mathrm{I}_{\mathrm{t}^{-}} K_{\mathrm{i}}^{\mathrm{app}}\right)+\left[\left(K_{\mathrm{i}}^{\mathrm{app}}+\mathrm{I}_{\mathrm{t}^{-}}\right.\right.\right.$ $\left.\left.\left.\mathrm{E}_{\mathrm{t}}\right)^{2}+4 \mathrm{E}_{\mathrm{t}} K_{\mathrm{i}}^{\mathrm{app}}\right]^{1 / 2}\right\}$

(where $\mathrm{V}_{\mathrm{o}}$ is the rate in the absence of inhibitor, $E_{t}$ is the total enzyme concentration, and $\mathrm{I}_{\mathrm{t}}$ is the total inhibitor concentration).

\section{Association Rate Constant Measurement ( $k_{\text {on }}$ )}

Association rate measurements $\left(k_{o n}\right)$ were performed by adding different concentrations of the TIMP mutants to ADAM10 (0.015nM). The rate of inhibition was followed using a continuous fluorometric assay at $27^{\circ} \mathrm{C}$ until steady state had been reached. The progress curves were analysed using the program Grafit and Equation 2 [17].

$\mathrm{P}=\mathrm{V}_{\mathrm{s}} \mathrm{t}+\left(\mathrm{V}_{\mathrm{o}}-\mathrm{V}_{\mathrm{s}}\right)\left(1-\mathrm{e}^{-\mathrm{kt}}\right) / \mathrm{k}$

(where $\mathrm{P}$ is the product concentration, $\mathrm{V}_{\mathrm{o}}$ the initial velocity, $\mathrm{V}_{\mathrm{s}}$ the steady state velocity and $\mathrm{k}$ the apparent first order rate constant of equilibrium between enzyme and TIMP complex). $k_{o n}$ values were calculated by linear regression of $\mathrm{k}$ on TIMP concentrations.

\section{CD44 shedding assay}

U251 glioblastoma cells were seeded the day before the experiment at $10^{5}$ cells/well 
in $24-$ well plates in $1 \mathrm{ml} 10 \%$ fetal calf serum (FCS)-enriched Dulbecco's modified Eagle's medium DMEMGlutamax ${ }^{\circledR}$ media (Invitrogen, UK). The following morning wells were washed twice with DMEM and the cells were incubated for $2 \mathrm{~h}$ in $300 \mu \mathrm{l}$ DMEM containing varying concentrations of the recombinant TIMPs or ADAM10 propeptide. Cells were stimulated by incubation with $5 \mu \mathrm{M}$ ionomycin for 30 minutes. Supernatants were then collected and analysed for soluble CD44 by ELISA according to the manufacturer's instructions.

Inhibition of CD44 shedding by ADAM10 siRNA

U251 cells were seeded in antibiotic-free growth medium in 24 well plates as before and incubated overnight at $37^{\circ} \mathrm{C}, 5 \% \mathrm{CO}_{2}$. The following day the cells were transfected with 4 siRNA duplexes targeting ADAM10 (siGenome individual duplexes, \# 1, 3, 4 and 5) or a scrambled control (Dharmacon RNA Technologies, USA) at a final concentration of $100 \mathrm{nM}$, according to the manufacturer's protocol. The cells were incubated at $37^{\circ} \mathrm{C}, 5 \% \mathrm{CO}_{2}$ for $48 \mathrm{~h}$ before stimulation with ionomycin $(5 \mu \mathrm{M})$ for 30 minutes as before. Cell supernatants were harvested and analysed for soluble CD44 by ELISA. Cells lysates were prepared in $40 \mu 1 /$ well cell lysis buffer $(50 \mathrm{mM}$ Tris- $\mathrm{HCl} \mathrm{pH} 8.0,150 \mathrm{mM}$ $\mathrm{NaCl}, 1 \%$ Triton $\mathrm{X}-100,0.02 \%$ sodium azide containing proteinase inhibitors;
EDTA $(5 \mathrm{mM})$, proteinase inhibitor cocktail III (1:100) (Calbiochem) and analysed by Western blotting for ADAM10.

\section{Western blotting}

Equivalent amounts of cell lysates were electrophoresed on reducing SDS $8 \%$ PAGE and the proteins transferred to nitrocellulose membranes overnight. ADAM10 was detected using a rabbit polyclonal antibody to human ADAM10 (1:500) and revealed with a secondary antibody conjugated to horseradish peroxidise. Membranes were stripped and reprobed for beta-actin as a loading

control.

Analysis of RNA expression in U251 cells

U251 cells were seeded at $5 \times 10^{5}$ cells /well in 6 well plates in antibiotic- free growth medium and incubated overnight at $37^{\circ} \mathrm{C}$. Triplicate wells were transfected as before with a smart pool of the 4 siRNA oligonucleotides targeting human ADAM10 used in the previously described shedding experiments. The cells were incubated at $37^{\circ} \mathrm{C}$ for $96 \mathrm{~h}$ and then total RNA was reverse transcribed and analysed for ADAM10 and ADAM17 gene expression by Taqman ${ }^{\circledR}$ real-time PCR.

\section{HB-EGF shedding assay}

MCF7-HB-EGF-AP cells were seeded at a density of $10^{5}$ cells/well in DMEM supplemented with $10 \%$ FCS and 
$600 \mu \mathrm{g} / \mathrm{ml}$ G418. After overnight incubation at $37^{\circ} \mathrm{C}, 5 \% \mathrm{CO}_{2}$ the cells were washed free of serum and incubated in DMEM $(300 \mu \mathrm{l} /$ well) for a further $2 \mathrm{~h}$. Recombinant TIMPs were added at varying concentrations for the final 30 mins. Shedding was induced by the addition of phorbol 12-myristate 13acetate (PMA, 100ng/ml) and incubation for a further $5 \mathrm{~h}$ at $37^{\circ} \mathrm{C}$. Cell supernatants were harvested and analysed for alkaline phosphatase activity as a measure of shed HB-EGF.

\section{Alkaline phosphatase activity assay}

Samples of conditioned medium were incubated for $18 \mathrm{~h}$ at $37^{\circ} \mathrm{C}$ in the presence of alkaline phosphatase substrate; $5 \mathrm{mM}$ nitrophenylphosphate, $1 \mathrm{mM}$ diethanolamine, $50 \mu \mathrm{M} \mathrm{MgCl}_{2}$ dissolved in alkaline phosphatase buffer $(0.15 \mathrm{M} \mathrm{NaCl}$, 0.5M Tris- $\mathrm{HCl} \mathrm{pH} 9.7,5 \mathrm{mM}$ EDTA). The absorbance of the coloured reaction product was measured at $420 \mathrm{~nm}$ in a microplate reader.

Inhibition of HB-EGF shedding by ADAM17 siRNA

MCF7-HB-EGF-AP cells were seeded into 24 well plates at a density of $10^{5}$ cells/well in antibiotic-free growth medium and incubated overnight at $37^{\circ} \mathrm{C}, 5 \%, \mathrm{CO}_{2}$. The following day the cells were transiently transfected with siRNA targeting ADAM17 (individual siGenome duplex \# 4) or a non-targeting control (\#1) according to the manufacturer's protocol
(Dharmacon RNA Technologies). The shedding assay was performed $48 \mathrm{~h}$ post transfection as described previously. Cell

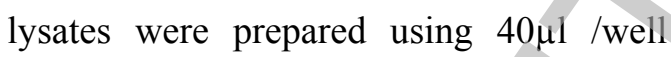
lysis buffer and analysed for ADAM17 protein expression by Western blotting, as before, using a rabbit polyclonal antibody to human ADAM17 (1:1000). Membranes were stripped and reprobed for alpha tubulin as a loading control.

\section{RESULTS}

\section{N-TIMPs are poor inhibitors of soluble ADAM10}

As a first step in delineating the ADAM10/TIMP interactions, we assessed the interaction of N-TIMPs and their fulllength counterparts with the soluble ectodomain of ADAM10 using a quenched fluorescent peptide assay. The binding constants $\left(K_{\mathrm{i}}^{\mathrm{app}}\right)$ and association rates $\left(k_{\mathrm{on}}\right)$, where measurable, are shown in Table I. $K_{\mathrm{i}}^{\text {app }}$ values for TIMP-1 and -3 against ADAM10 are comparable to those of TIMP-3 and N-TIMP-3 against ADAM17. In comparison to full length TIMP-1 and TIMP-3, their N-TIMP counterparts were unable to efficiently inhibit ADAM10. Furthermore, the mutant N-TIMPs, NTIMP-1 ${ }^{\text {tace }}$, N-TIMP-2 ${ }^{\text {tace }}$ and N-TIMP-4 ${ }^{\text {tace }}$ engineered to inhibit ADAM17 [15-18] had no activity against ADAM10 in this assay (Table1). Neither TIMP-2, nor TIMP-4, nor their N-terminal counterparts 
showed detectable inhibition of ADAM10 (data not shown).

\section{Analysis of TIMP activities against cellular ADAM10 and ADAM17}

We utilised the inhibition of CD44 shedding by the highly invasive glioblastoma cell line $\mathrm{U} 251$ for the analysis of the efficacy of the various TIMPs against native ADAM10. Initially, in order to establish that shedding was ADAM10 mediated, we used specific siRNA to knockdown ADAM10 and showed that CD44 shedding was compromised (Figure 1a). Reduced ADAM10 expression was confirmed by analysis of RNA levels by real time PCR. ADAM17 RNA levels were unaffected by expression of ADAM- 10 siRNA (Figure 1b). In addition, Western blotting of lysates from cells transfected with ADAM10 siRNA showed a significant decrease in ADAM10 protein levels compared to mock transfected cells or those transfected with a non-targeting siRNA control (Figure 1c). Recombinant ADAM10 propeptide has previously been shown to be a potent inhibitor of ADAM10 mediated shedding of EGF receptor ligands [24]. We were able to demonstrate that it also inhibited CD44 shedding in our assay, in a dose dependent manner (Figure 2), further confirming that ionomycin stimulated shedding in these cells is ADAM10 mediated.

We assessed the behaviour of the $\mathrm{N}-$ terminal TIMPs in comparison to full length TIMPs in cell based shedding of CD44 (Figure 3). In this experiment we observed 37\% inhibition with TIMP-1 at the highest dose tested $(500 \mathrm{nM})$ but only $6 \%$ inhibition with N-TIMP-1 at the same concentration. As expected TIMP-3 was an efficient inhibitor of shedding at $500 \mathrm{nM}$ (72\% inhibition; IC50 100nM) but surprisingly, N-TIMP-3 had no activity. Full length TIMP-2 and N-TIMP-2 were also very inefficient inhibitors of shedding (data not shown). We next examined the effects of the N-TIMP mutants with activity towards ADAM17 on ADAM10 mediated shedding. Surprisingly, although no measurable interaction could be obtained for N-TIMP-1 ${ }^{\text {tace }}$ against the soluble ADAM10 ectodomain using a small peptide substrate (Table 1), the mutant showed a dose dependent inhibition of CD44 shedding. No inhibition of shedding was seen with $\mathrm{N}$ TIMP-2 ${ }^{\text {tace }}$ or N-TIMP-4 ${ }^{\text {tace }}$ (Figure 4 ). In contrast, ADAM17 mediated HB-EGF shedding in an MCF7 model system was efficiently inhibited by both full length (data not shown) and N-TIMP-3. At the highest concentration tested $(1 \mu \mathrm{M}) \mathrm{N}$ TIMP-1 $1^{\text {tace }}$ also inhibited shedding by more than $80 \%$ and N-TIMP-2 $2^{\text {tace }}$ by nearly $50 \%$ (Figure 5). We confirmed that PMA stimulated HB-EGF shedding in these cells was ADAM17 mediated by transiently knocking down ADAM17 using specific siRNA and demonstrated that shedding was compromised (Figure 6). Additionally ADAM10 propeptide had 
no inhibitory activity against HB-EGF shedding in these assays (data not shown).

\section{DISCUSSION}

Although ADAM10 was discovered several years ago, its physiological substrates remain controversial and elusive. Since it bears sequence similarities with ADAM17 and there is a degree of substrate overlap, the development of inhibitors that distinguish the two activities has been pursued. We originally showed that TIMP-1 can inhibit ADAM10 and, to date this appears to be a specific activity against this ADAM, compared to TIMP-3 which inhibits ADAMs 10, 12 and 17. Previously we found that TIMP-1 was a marginally better ADAM10 inhibitor relative to TIMP-3 [3]. In this study we used a lower temperature and a different substrate and observed that TIMP-3 was a slightly more efficient inhibitor of ADAM10. The measurement of association constants is rather inefficient using these substrates and the margins of error large and we conclude that the two TIMPs are of comparable efficacy against the soluble form of ADAM10. To distinguish between ADAM10 and ADAM17 a number of studies have used two low molecular weight inhibitors, GW280264X ((2R,3S)3-(formyl-hydroxyamino)-2-(2-methyl-1propyl) hexanoic acid [(1S)-5benzyloxycarbamoylamino-1-(1,3-thiazol- 2-ylcarbamoyl)-1-pentyl] amide) and GI254023X ((2R,3S)-3-(formylhydroxyamino)-2-(3-phenyl-1-propyl) butanoic acid[(1S)-2,2-dimethyl-1methylcarbamoyl-1-propyl] amide); both inhibit ADAM10, but only the former inhibits ADAM17 [25, 26]. Recently, the propeptide of ADAM10 has also been used to identify its shedding activity [24]. Systematic modification of the MMPbinding ridge of the inhibitory domain of TIMP-1, -2, and -4 [14-18] has identified key residues that are important for ADAM17 specificity. In this study we aimed to investigate whether the mutant TIMPs would inhibit ADAM10 in biochemical and cell-based assays. We first wanted to establish whether the inhibitory domains of TIMPs (N-TIMPs) were sufficient for ADAM10 inhibition. Kinetic analysis clearly showed that even at high concentrations $(500 \mathrm{nM})$ none of the 4 N-TIMPs was able to inhibit ADAM10 enzymatic activity. When the full-length inhibitors were tested using the same kinetic assay we found that TIMP-1 and TIMP-3 were able to inhibit ADAM10 with $\mathrm{Ki}$ values of: $0.1 \mathrm{nM}$ and $0.5 \mathrm{nM}$ respectively. In comparison, we have previously shown that binding of TIMP-1, -2 or -3 to MMP 2 was markedly reduced by loss of the C-terminal domain [27, 29]. We also found that the extra-catalytic domains of ADAM17 interfered with TIMP-3 binding [14], implying interactions outside the TIMP N-terminal 
ridge- catalytic cleft sites defined in the existing TIMP-MMP structures [11, 12].

In our previous studies we have identified the key residues of N-TIMPs that are essential for ADAM17 specificity. In this study we tested the N-TIMP-1, N-TIMP-2 and N-TIMP-4 variants previously designed and shown to be potent inhibitors of ADAM17 against ADAM10. These NTIMP variants were not able to form stable complexes with soluble recombinant ADAM10 and it was not possible to obtain any values either for the binding affinity or the association rates of these inhibitors with the enzyme.

We used a cell based shedding assay to establish whether the findings obtained from our kinetic studies of soluble ADAM10 reflected TIMP inhibitory activity against the native enzyme. Shedding of the hyaluronan receptor, CD44, from the surface of U251 cells can be stimulated by short incubations with ionomycin. Silencing of ADAM10 by siRNA significantly knocked down both RNA and protein expression and additionally inhibited stimulated shedding. The result indicates that this shedding activity is ADAM10 specific. Dose dependent inhibition of stimulated CD44 shedding using recombinant ADAM10 propeptide further confirmed the role of ADAM10.

Broadly speaking the data obtained from our cell based assay agreed with that obtained in our kinetic studies. Both full length TIMPs-1 and-3 inhibited CD44 shedding though TIMP-3 was consistently more efficient than TIMP-1. N-TIMP-1 had a very low level of inhibitory activity whereas N-TIMP-3 was totally unable to inhibit shedding at any concentration tested. Surprisingly the N-TIMP-1 variant previously designed to be a potent inhibitor of ADAM17, N-TIMP-1 ${ }^{\text {tace, }}$, showed a dose responsive inhibition of CD44 shedding. However N-TIMP-2 $2^{\text {tace }}$ and N-TIMP-4 ${ }^{\text {tace }}$ remained ineffective. We conclude that interaction of ADAM10 with the cell bound CD44 substrate modified the ability of N-TIMP-1 $1^{\text {tace }}$ to inhibit shedding. In contrast N-TIMP-3 and the N-TIMP ${ }^{\text {tace }}$ variants were efficient inhibitors of ADAM17 mediated HB-EGF shedding confirming that the mechanism by which TIMPs inhibit ADAM10 activity differs from that of ADAM17. It is clear that, unlike ADAM17, for ADAM10 inhibition the C-terminal domain of TIMP3 is indispensable for the interaction with the enzyme. We may speculate that efficient TIMP-3 inhibition of native ADAM10 depends on a specific alignment or configuration of enzyme, inhibitor and substrate that requires the C-terminal domain of TIMP-3. This can probably be attributed to the spatial distribution of TIMP-3 in the cell system, possibly involving its sequestration to the extracellular matrix. Yu et al. [28] showed that TIMP-3 bound to glycosaminoglycans within the extracellular matrix. Furthermore heparin and heparin sulphate have been shown to enhance the activity of 
TIMP-3 against MMP-2 [29], MMP-13 and ADAM17 (P. Dodds, M.H. Lee and G. Murphy, unpublished). Chondroitin 6 ACKNOWLEDGEMENTS: We thank the sulphate and heparan sulphate also enhance TIMP-3 binding to ADAM-TS4 [30] (G. Wayne, A. Amour and G Murphy, unpublished). Our recent study identified motifs in both the N-terminal and Cterminal domains of TIMP-3 that are essential for ECM binding [31]. The data from the cell based assays of ADAM activity suggest that soluble TIMPs are less efficient for ADAM10 inhibition than ECM bound TIMPs. However, the results from our kinetic assays using a fluorigenic peptide indicate that the $\mathrm{C}$-terminal domains of TIMP-1 and -3 must also interact directly with the ectodomain of soluble ADAM10 for efficient inhibition Overall these results suggest that $\mathrm{C}$ terminal domain interactions play an important role in ADAM10 inhibition. We have been unable to prepare isolated recombinant $\mathrm{C}$-terminal sub-domains to assess their independent ability to bind to ADAM10.

The difference in the inhibitory behaviour of full length and C-terminally truncated TIMPs with respect to ADAM17 and ADAM10 could pave the way to the development of selective inhibitors. Further investigation is needed in order to establish which epitopes of the C-terminal domains of TIMPs are crucial for ADAM10 inhibition in order to understand the TIMP/ADAM10 inhibition mechanism. European Union Framework Programme 6 (LSHC-CT-2003-503297), the Medical Research Council, UK, Biotechnology and Biological Sciences Research Council, UK and Cancer Research UK for funding. Thanks to Peter Stanley for discussions. 


\section{REFERENCES}

1. Becherer, J.D., and Blobel, C.P. (2003) Biochemical properties and functions of membrane-anchored metalloprotease-disintegrin proteins (ADAMs). Curr. Top. Dev. Biol. 54, 101-23.

2. Huang J., Bridges L.C., White J.M. (2005) Selective Modulation of Integrinmediated Cell Migration by Distinct ADAM Family Members. Mol. Biol. Cell 16, 4982-91.

3. Amour A., Knight C.G., Webster A., Slocombe P.M., Stephens P.E., Knauper V., Docherty A.J., Murphy G. (2000) The in vitro activity of ADAM10 is inhibited by TIMP-1 and TIMP-3. FEBS Lett. 473, 275-9

4. Apte, S.S., Olsen, B.R., Murphy, G. (1995) The Gene Structure of Tissue Inhibitor of Metalloproteinases (TIMP)-3 and Its Inhibitory Activities Define the Distinct TIMP Gene Family. J. Biol. Chem. 270, 14313-8

5. Amour, A., Slocombe, P. M., Webster, A., Butler, M., Knight, C. G., Smith, B. J., Stephens, P. E., Shelley, C., Hutton, M., Knauper, V., Docherty, A. J., and Murphy, G. (1998) TNF-alpha converting enzyme (TACE) is inhibited by TIMP-3. FEBS Lett. 435, 39-44

6. Loechel, F., Fox, J.W., Murphy, G., Albrechtsen, R., Wewer, U.M. (2000) ADAM 12-S cleaves IGFBP-3 and IGFBP-5 and is inhibited by TIMP-3. Biochem Biophys Res Commun. 278, 511-5.

7. Kashiwagi, M., Tortorella, M. D., Nagase, H., and Brew, K. (2001) TIMP-3 Is a Potent Inhibitor of Aggrecanase 1 (ADAM-TS4) and Aggrecanase 2 (ADAM-TS5). J. Biol. Chem. 276, 12501-12504

8. Murphy, G., Houbrechts, A., Cockett, M. I., Williamson, R. A., O'Shea, M., and Docherty, A. J. P. (1991) The N-terminal domain of tissue inhibitor of metalloproteinases retains metalloproteinase inhibitory activity. Biochemistry 30, $8097-8102$

9. Nguyen, Q., Willenbrock, F., Cockett, M. I., O'Shea, M., Docherty, A. J. P., and Murphy, G. (1994) Different Domain Interactions Are Involved in the Binding of Tissue Inhibitors of Metalloproteinases to Stromelysin-1 and Gelatinase A. Biochemistry 33, 2089-2095

10. Huang, W., Suzuki, K., Nagase, H., Arumugam, S., Van Doren, S. R., and Brew, K. (1996) Folding and characterization of the amino-terminal domain of 
human tissue inhibitor of metalloproteinases-1 (TIMP-1) expressed at high yield in E. coli. FEBS Lett. 384, 155-161

11. Gomis-Rüth, F., Maskos, K., Betz, M., Bergner, A., Huber, R., Suzuki, K., Yoshida, N., Nagase, H., Brew, K., Bourenkov, G. P., Bartunik, H., and Bode, W. (1997) Mechanism of inhibition of the human matrix metalloproteinase stromelysin-1 by TIMP-1. Nature 389, 77-81

12. Fernandez-Catalan, C., Bode, W., Huber, R., Turk, D., Calvete, J. J., Lichte, A., Tschesche, H., and Maskos, K. (1998) Crystal structure of the complex formed by the membrane type 1-matrix metalloproteinase with the tissue inhibitor of metalloproteinases-2, the soluble progelatinase A receptor. EMBO J. 17, 5238-5248

13. Murphy, G., and Knauper, V. (1997) Relating matrix metalloproteinase structure to function: why the "hemopexin" domain? Matrix Biol. 15, 511-518

14. Lee, M.H., Verma, V., Maskos, K., Becherer, J.D., Knauper, V., Dodds, P., Amour, A., and Murphy, G. (2002) The C-terminal domains of TACE weaken the inhibitory action of N-TIMP-3. FEBS Lett. 520, 102-6

15. Lee, M.H., Maskos, K., Knäuper, V., Dodds, P., and Murphy, G. (2002) Mapping and characterization of the functional epitopes of tissue inhibitor of metalloproteinases (TIMP)-3 using TIMP-1 as the scaffold: a new frontier in TIMP engineering. Protein Sci. 11, 2493-503

16. Lee, M. H., Rapti, M., Knäuper, V., and Murphy, G. (2004) Delineating the molecular basis of the inactivity of tissue inhibitor of metalloproteinase-2 against tumor necrosis factor-alpha-converting enzyme. J. Biol. Chem. 279, 45121-9

17. Lee, M. H., Rapti, M., Knäuper, V., and Murphy, G. (2004) Threonine 98, the pivotal residue of tissue inhibitor of metalloproteinases (TIMP)-1 in metalloproteinase recognition. J. Biol. Chem. 279, 17562-17569

18. Lee, M. H., Rapti, M., Knäuper, V., and Murphy, G. (2005) Total conversion of tissue inhibitor of metalloproteinase (TIMP) for specific metalloproteinase targeting: fine-tuning TIMP-4 for optimal inhibition of tumor necrosis factor\{alpha\}-converting enzyme. J. Biol. Chem. 280, 15967-75

19. Hartmann, D., Strooper, B., Serneels, L., Craessaerts, K., Herreman, A., Annaert, W., Umans, L., Lubke, T., Illert, A.L., von Figura, K., and Saftig, P. (2002) The disintegrin/metalloprotease ADAM 10 is essential for Notch 
signalling but not for alpha-secretase activity in fibroblasts. Human Molecular Genetics. 11, 2615-2624

20. Maretzky, T., Reiss, K., Ludwig, A., Buchholz,J., Scholz, F., Proksch, E., de Strooper, B., Hartmann, D., and Saftig, P. (2005) ADAM10 mediates Ecadherin shedding and regulates epithelial cell-cell adhesion, migration, and beta-catenin translocation. Proc Natl Acad Sci. 102, 9182-7

21. Janes, W.P., Saha, N., Barton, W.A., Kolev, M.V., Wimmer-Kleikamp, S.H., Nievergall, E., Blobel, C.P., Himanen, J-P., Lackmann, M., and Nikolov, D.B. (2005) Adam meets Eph: an ADAM substrate recognition module acts as a molecular switch for ephrin cleavage in trans. Cell 123, 291-304

22. Obregon, DF., Rezai-Zadeh, K., Bai, Y., Sun, N., Hou, H., Ehrhart, J., Zeng, J., Mori, T., Arendash, GW., Shytle, D., Town, T., and Tan, J. (2006) ADAM10 activation is required for green tea (-)-epigallocatechin-3-gallateinduced alpha-secretase cleavage of amyloid precursor protein. J. Biol. Chem. 281, 16419-27

23. Vincent, B., Paitel, E., Saftig, P., Frobert, Y., Hartmann, D., de Strooper, B., Grassi, J., Lopez-Perez, E., and Checler, F. (2001) The Disintegrins ADAM10 and TACE Contribute to the Constitutive and Phorbol Ester-regulated Normal Cleavage of the Cellular Prion Protein. J. Biol. Chem. 276, 37743-37746

24. Moss ML, Bomar M, Liu Q, Sage H, Dempsey P, Lenhart PM, Gillispie PA, Stoeck A, Wildeboer D, Bartsch JW, Palmisano R, Zhou P. (2007) The ADAM10 prodomain is a specific inhibitor of ADAM10 proteolytic activity and inhibits cellular shedding events. J. Biol. Chem. 282, 35712-21

25. Gough, PJ., Garton, KL., Wille, PT., Rychlewski, M., Dempsey, PJ., and Raines, EW. (2004) A disintegrin and metalloproteinase 10-mediated cleavage and shedding regulates the cell surface expression of CXC chemokine ligand 16. J. Immunol. 172, 3678-85

26. Maretzky T, Schulte M, Ludwig A, Rose-John S, Blobel C, Hartmann D, Altevogt P, Saftig P, Reiss K. (2005) L1 is sequentially processed by two differently activated metalloproteases and presenilin/gamma-secretase and regulates neural cell adhesion, cell migration, and neurite outgrowth. Mol Cell Biol. 25, 9040-53.

27. Willenbrock, F., Crabbe, T., Slocombe, P.M., Sutton, C.W., Docherty, A.J., Cockett, M.I., O’Shea, M., Brocklehurst, K., Phillps, I.R., and Murphy, G. 
(1993) The activity of the tissue inhibitors of metalloproteinases is regulated by C-terminal domain interactions: a kinetic analysis of the inhibition of gelatinase A. Biochemistry 32, 4330-7

28. Yu WH, Yu S, Meng Q, Brew K, Woessner JF Jr. (2000) TIMP-3 binds to sulfated glycosaminoglycans of the extracellular matrix. J. Biol. Chem. 275, 31226-32

29. Butler GS, Apte SS, Willenbrock F, Murphy G. (1999) Human tissue inhibitor of metalloproteinases 3 interacts with both the $\mathrm{N}$ - and C-terminal domains of gelatinases A and B. Regulation by polyanions. J Biol Chem. 274,10846-51

30. Wayne GJ, Deng SJ, Amour A, Borman S, Matico R, Carter HL, Murphy G. (2007) TIMP-3 inhibition of ADAMTS-4 (Aggrecanase-1) is modulated by interactions between aggrecan and the C-terminal domain of ADAMTS-4. J. Biol. Chem. 282, 20991-8

31. Lee, M.H., Atkinson, S.J., and Murphy, G. (2007) Identification of the extracellular matrix (ECM) binding motifs of tissue inhibitor of metalloproteinases (TIMP)-3 and effective transfer to TIMP-1. J. Biol. Chem. 282, 6887-98 


\section{FIGURE LEGENDS}

\section{Figure 1}

Transient knockdown of ADAM10 in U251 cells.

\section{a) Inhibition of ionomycin stimulated CD 44 shedding.}

U251 cells were transiently transfected with 4 different siRNA oligonucleotides against ADAM10. After 48h the CD44 shedding assay was performed as described in the text. All 4 siRNAs significantly inhibited CD44 shedding compared to the scrambled control or mock transfected cells. Solid bars, cells stimulated with ionomycin, open bars, unstimulated cells.

\section{b) RNA analysis.}

U251 cells were transiently transfected with a smart pool of 4 ADAM10 specific siRNA oligonucleotides or a non-targeting control and levels of ADAM10 (left panel) or ADAM17 RNA (right panel) were analysed by Taqman ${ }^{\circledR}$ real time PCR.

\section{c) Western Blotting.}

U251 cell lysates from a) were analysed by Western blotting for ADAM10 (upper panel) then reprobed for beta actin (lower panel). Lane 1, untransfected cells, lane 2, mock transfected cells, lane3, cells transfected with the scrambled control siRNA, lanes 4-7, cells transfected with ADAM10 siRNAs 1, 3, 4 and 5 respectively.

\section{Figure 2}

Inhibition of CD44 shedding by recombinant ADAM10 propeptide.

U251 cells were incubated for $2 \mathrm{~h}$ at $37^{\circ} \mathrm{C}$ with varying concentrations of recombinant ADAM10 propeptide (solid bars) or equivalent amounts of control buffer, $(25 \mathrm{mM}$ Tris- $\mathrm{HCl} \mathrm{pH} \quad 8.0,100 \mathrm{mM} \mathrm{NaCl}, \quad 50 \mathrm{mM} \mathrm{CaCl} 2, \quad 10 \%$ glycerol, $0.1 \%$ beta mercaptoethanol) (open bars). Shedding was stimulated (open and solid bars) by the addition of $5 \mu \mathrm{M}$ ionomycin. Cell supernatants were analysed for soluble CD44 by ELISA. Striped bar indicates basal shedding in unstimulated cells. 


\section{Figure 3}

\section{Inhibition of CD44 shedding in U251 glioblastoma cells.}

U251 cells were incubated for 30 mins with $5 \mu \mathrm{M}$ ionomycin in the presence of varying concentrations of N-terminal (NT) or full length TIMPs (FLT). Cell supernatants were analysed for soluble CD44 by ELISA. Only full length TIMPs -1 and -3 were effective inhibitors of shedding. Data is expressed as the $\%$ inhibition of stimulated shedding where inhibition of shedding in the absence of TIMPs is taken as $0 \%$.

\section{Figure 4}

\section{Effect of N-TIMP ${ }^{\text {tace }}$ mutants on CD44 shedding.}

$\mathrm{U} 251$ cells were incubated at $37^{\circ} \mathrm{C}$ for $1 \mathrm{~h}$ in the presence or absence of varying concentrations of N-TIMP ${ }^{\text {tace }}$ mutants. Shedding was stimulated by the addition of $5 \mu \mathrm{M}$ ionomycin and a further incubation at $37^{\circ} \mathrm{C}$ for $30 \mathrm{mins}$. Shed CD44 in the cell supernatants was analysed by ELISA. Data is expressed as the \% inhibition of stimulated shedding where inhibition of shedding in the absence of TIMPs is taken as $0 \%$.

\section{Figure 5}

Effect of N-TIMP ${ }^{\text {tace }}$ mutants on HB-EGF shedding.

MCF-7-HB-EGF-AP cells were incubated for $5 \mathrm{~h}$ with 100ng/ml PMA in the presence or absence of varying concentrations of wild type N-TIMPs -1, -2 and -3 (solid lines) or N-TIMP-1 $1^{\text {tace }}$ and N-TIMP-2 ${ }^{\text {tace }}$ mutants (dotted lines). Cell supernatants were analysed for alkaline phosphatase activity as a measure of shed HB-EGF as described. Data is expressed as the \% inhibition of stimulated shedding where inhibition of shedding in the absence of TIMPs is taken as $0 \%$. 


\section{Figure 6}

\section{a) Inhibition of HB-EGF shedding by ADAM17 knockdown}

MCF-7-HB-EGF-AP cells were transiently transfected with A17 siRNA or a scrambled control. After $48 \mathrm{~h}$ the HB-EGF shedding assay was performed as described in the text and the cell supernatants analysed for alkaline phosphatase activity. Solid bars, cells stimulated with 100ng/ml PMA, shaded bars, unstimulated cells.

\section{b) Western blot for ADAM17}

Cell lysates from a) were analysed by Western blotting for ADAM17 protein expression. Lanes 1, 3, 5, and 7 were from unstimulated cells and lanes 2, 4, 6 and 8 were from PMA stimulated cells. Lanes1, 2, untransfected, lanes 3, 4 mock transfected, lanes 5, 6, cells transfected with ADAM17 siRNA, lanes 7, 8 cells transfected with scrambled control siRNA. 
Table I: Apparent inhibition constants $\left(K_{i}^{\text {app }}\right)$ and association rate $\left(k_{\text {on }}\right)$ for the interaction of full-length TIMP-1 and TIMP-3 and the N-TIMPs with ADAM10 or ADAM17. N-TIMPs are not able to form tight-binding complex with ADAM10. Hence, there is no visible enzyme-inhibitor association curve. NA, not able to determine.

\begin{tabular}{|c|c|c|c|c|}
\hline & $K_{\mathrm{i}}^{\text {app }}\left(\mathrm{x10}^{-9} \mathrm{M}\right)$ & $K_{\mathrm{i}}^{\text {app }}\left(\times 10^{-9} \mathrm{M}\right)$ & $k_{\text {on }}\left(\times 10^{-4} M^{-1} s^{-1}\right)$ & $k_{\text {on }}\left(x 0^{-5} M^{-1} s^{-1}\right)$ \\
\hline & ADAM10 & ADAM17 & ADAM10 & ADAM17 \\
\hline TIMP-1 & $0.5 \pm 0.003$ & $>1000$ & $2.2 \pm 0.03$ & NA \\
\hline TIMP-3 & $0.1 \pm 0.005$ & 0.2 & $2.8 \pm 0.05$ & 9.94 \\
\hline N-TIMP-1 & $>1000$ & 356 & NA & NA \\
\hline N-TIMP-3 & $>1000$ & 0.22 & $\mathrm{NA}$ & 3.65 \\
\hline $\mathrm{NT} 1^{\text {tace }}$ & $>1000$ & 0.14 & $\mathrm{NA}$ & 0.76 \\
\hline $\mathrm{NT} 2^{\text {tace }}$ & $>1000$ & 1.49 & NA & 0.57 \\
\hline NT4 ${ }^{\text {tace }}$ & $>1000$ & 0.73 & $\mathrm{NA}$ & 0.114 \\
\hline
\end{tabular}


a)

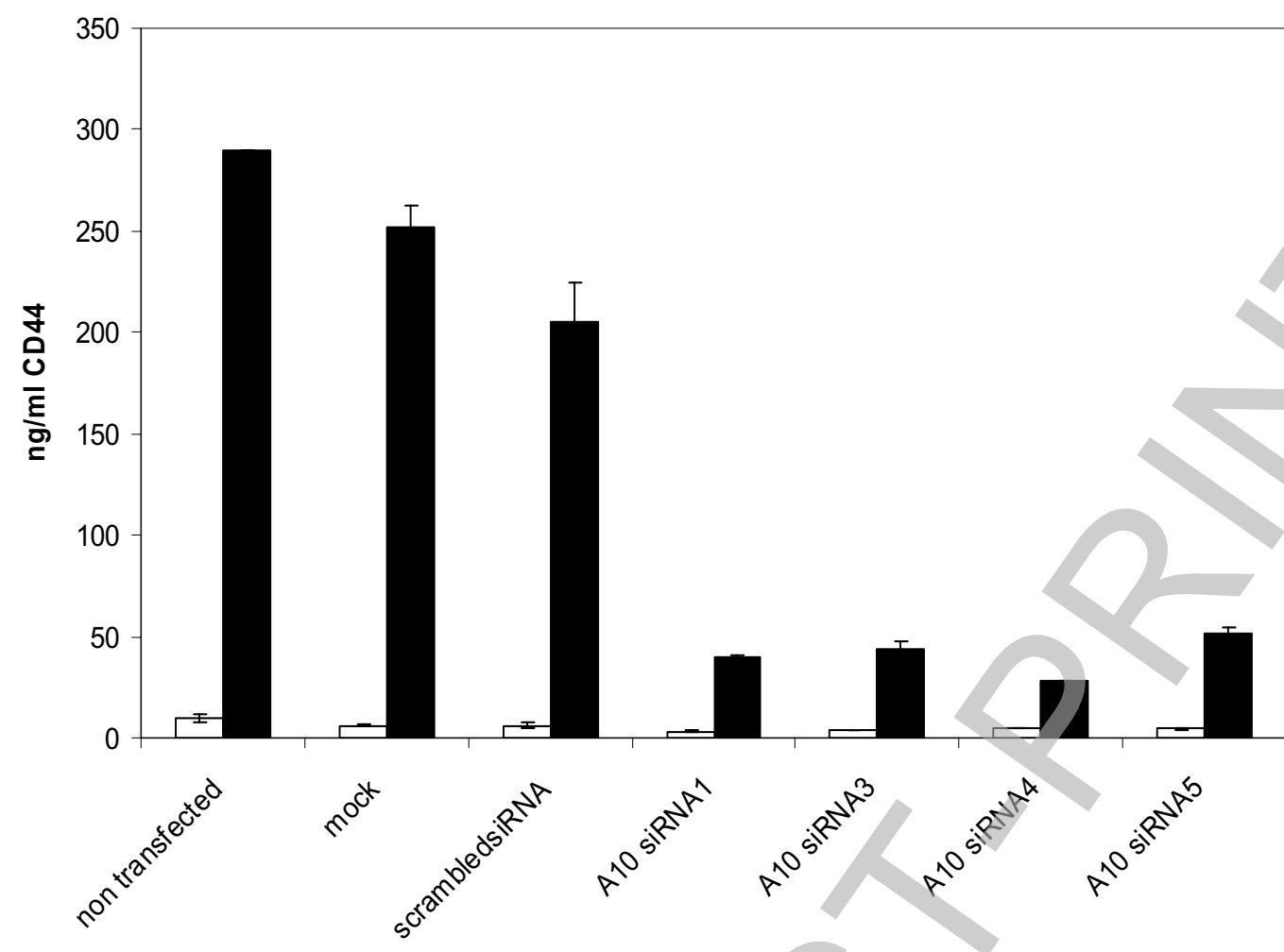

b)

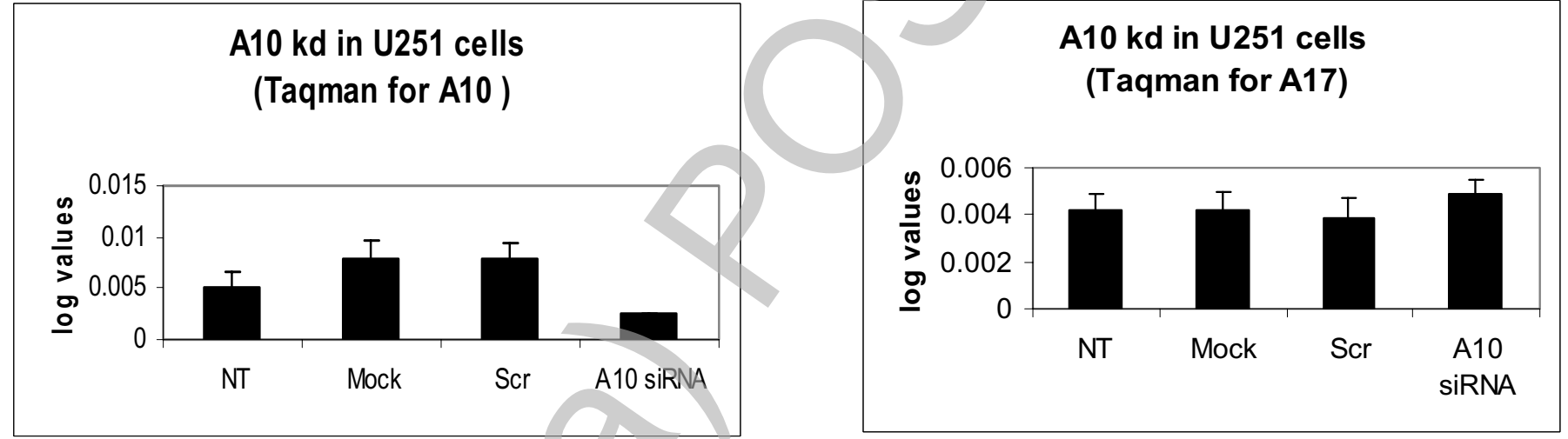

c)

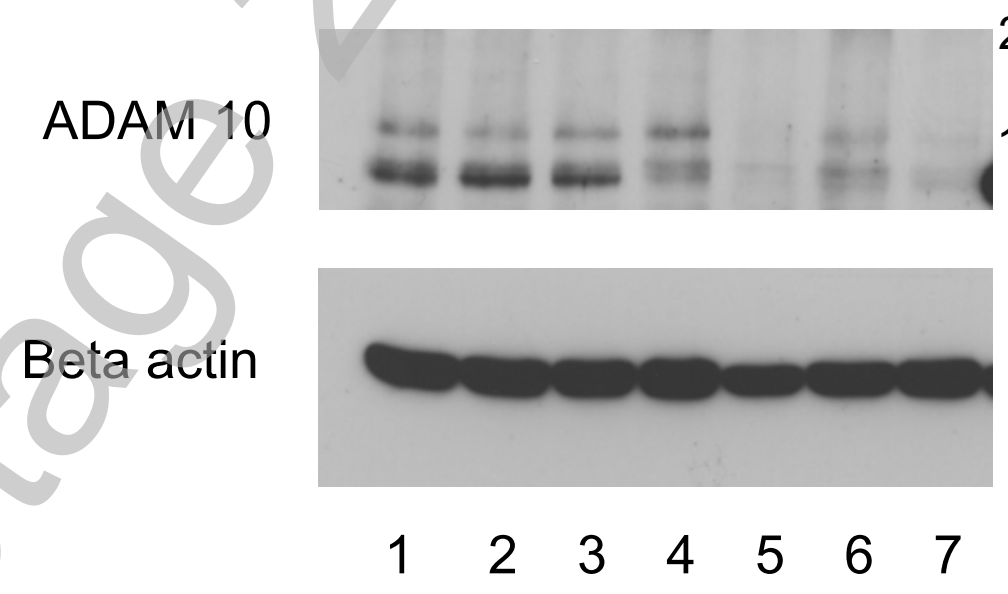

\section{Figure 1}

Licenced copy. Copying is not permitted, except with prior permission and as allowed by law. (C) 2008 The Authors Journal compilation (C) 2008 Biochemical Society 


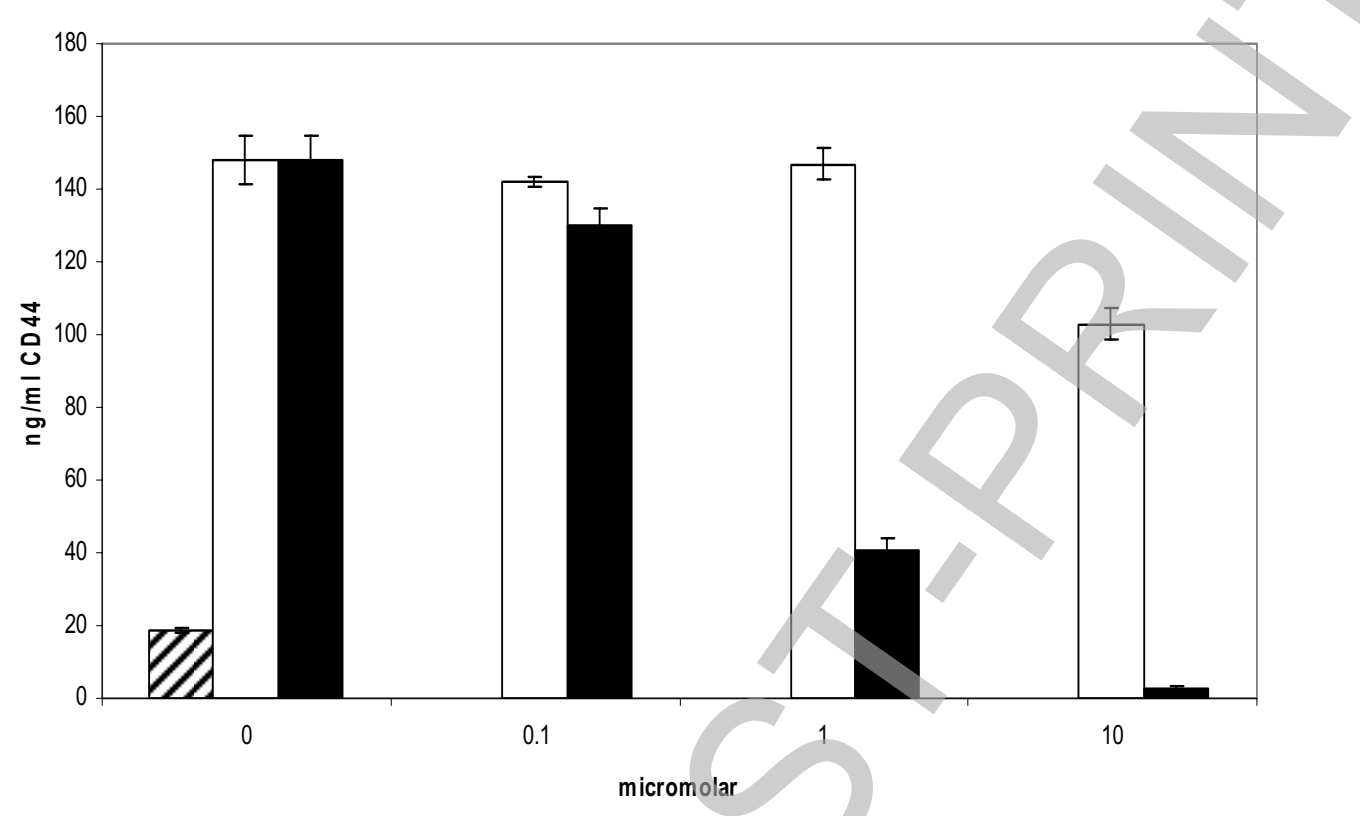

Figure 2

Licenced copy. Copying is not permitted, except with prior permission and as allowed by law. (C) 2008 The Authors Journal compilation (C) 2008 Biochemical Society 
Biochemical Journal Immediate Publication. Published on 10 Jan 2008 as manuscript BJ20071430

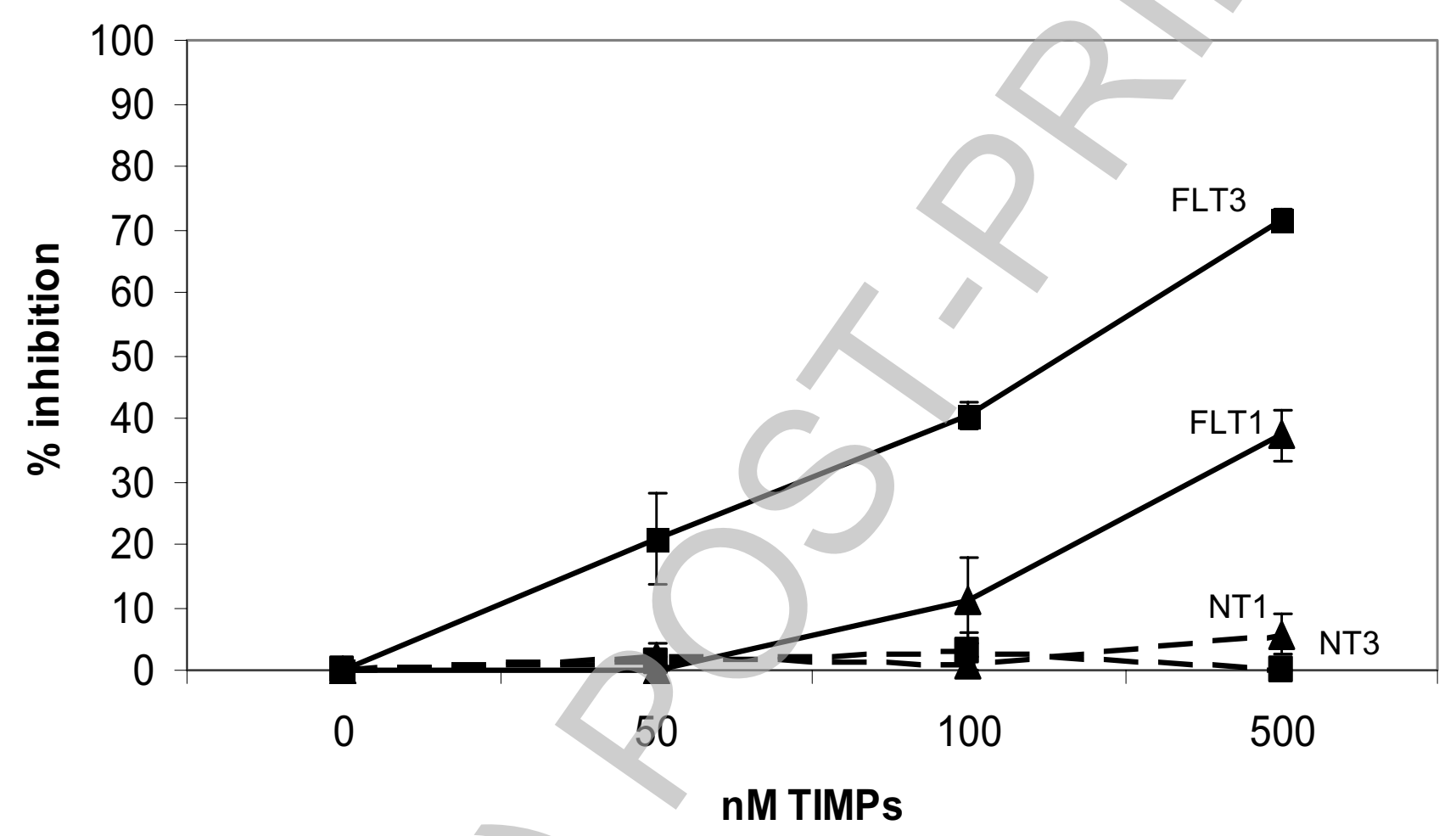

Figure 3

Licenced copy. Copying is not permitted, except with prior permission and as allowed by law. (C) 2008 The Authors Journal compilation (C) 2008 Biochemical Society 
B Biochemical Journal Immediate Publication. Published on 10 Jan 2008 as manuscript BJ20071430

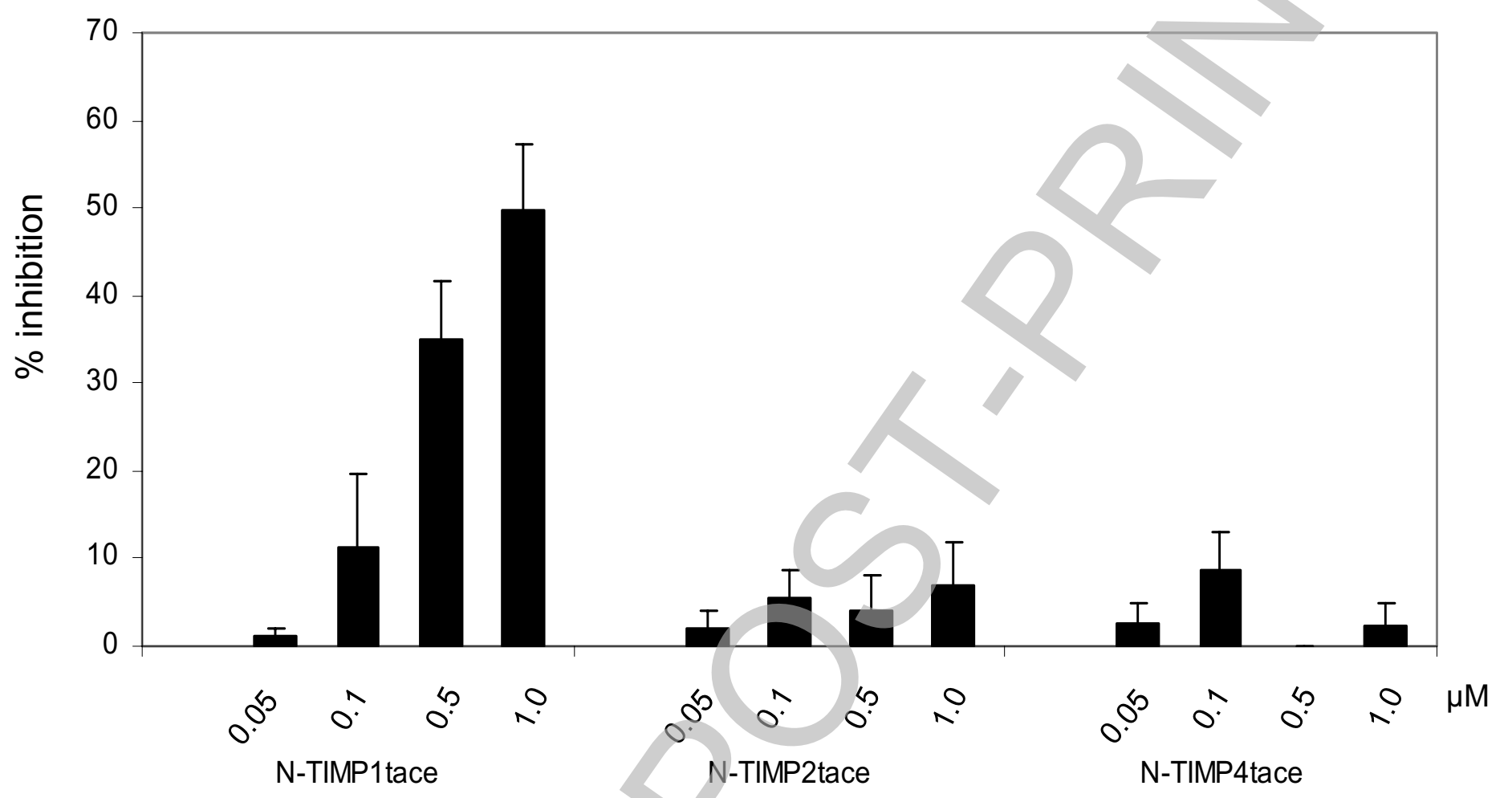

Figure 4

Licenced copy. Copying is not permitted, except with prior permission and as allowed by law. (c) 2008 The Authors Journal compilation (c) 2008 Biochemical Society 


\section{Inhibition of HB-EGF shedding}

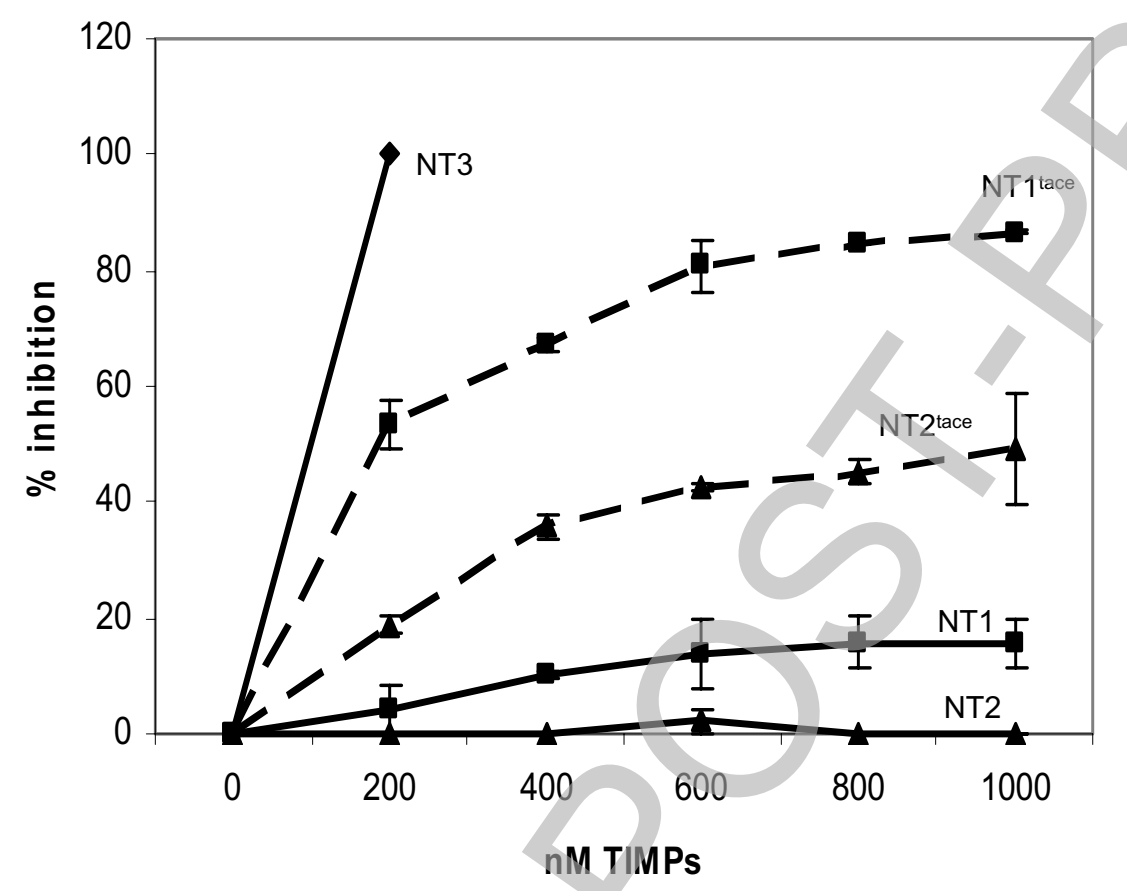

\section{Figure 5}

Licenced copy. Copying is not permitted, except with prior permission and as allowed by law. (C) 2008 The Authors Journal compilation (C) 2008 Biochemical Society 
Biochemical Journal Immediate Publication. Published on 10 Jan 2008 as manuscript BJ20071430

a)

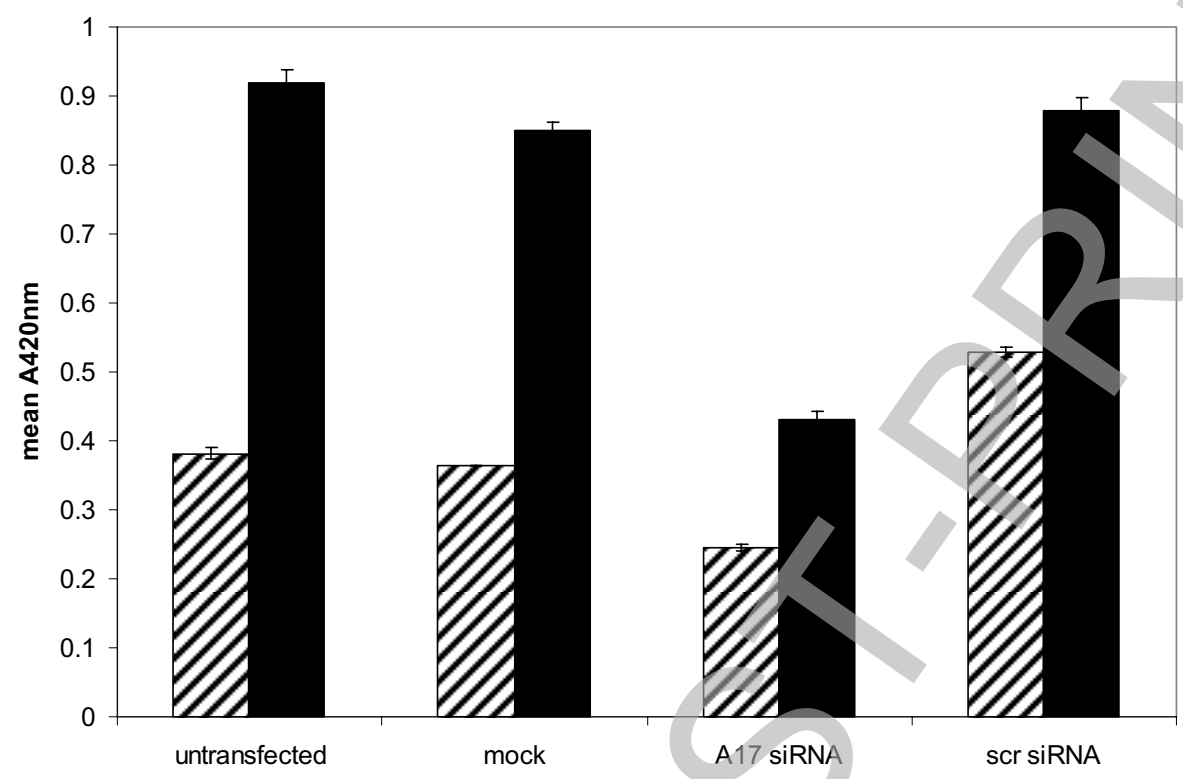

b)

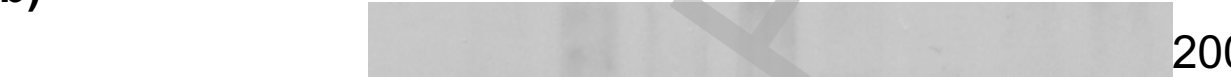

ADAM 17

200

Alpha tubulin

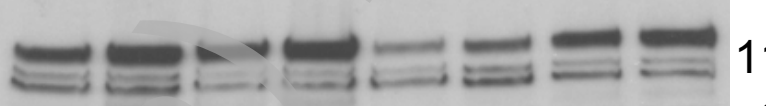

116

97

66

45

31

$-\quad+\quad+\quad+\quad+\quad-\quad+$ PMA

$\begin{array}{llllllll}1 & 2 & 3 & 4 & 5 & 6 & 7 & 8\end{array}$

Figure 6 